\title{
Constructing the evaluation index system of auxiliary service of wind power based on the SEM
}

\author{
Ren Lingzhi* ${ }^{1}$, Wang Ling ${ }^{2}$, Zhao Xin-gang ${ }^{1}$ \\ ${ }^{1}$ School of Economics and Management, North China Electric Power Univ., Beijing China \\ ${ }^{2}$ State Grid Liaoning Electric power co., LTD. Benxi Power Supply Company, Benxi, China
}

841229874@qq.com.

Keyword: Wind power; Auxiliary service; Comprehensive evaluation; SEM

\begin{abstract}
With the rapid development of wind power, the conventional power auxiliary services have not met the requirements of wind power grid-connected power generation in full. In order to relieve the grid-connected and integration issues of wind power, wind power was put forward to participate in ancillary ser-vices on the basis of related research. Aiming at the feasibility problem of wind power auxiliary service, the paper builded the evaluation index system for wind power auxiliary services firstly. Secondly, the article constructed the evaluation model of wind power auxiliary services based on structural equation model (SEM), and researched the identification and application of the SEM of wind power auxiliary services. Finally, the conclusion was presented.
\end{abstract}

\section{INSTRUCTION}

At present, the power auxiliary services in China are taken on by the traditional power supply, mainly including small coal-fired power plants and pumped storage power plants. However, with the rapid development of intermittent energy, especially the wind power, it is increasingly difficult for the traditional auxiliary services to maintain the safe operation of power system. Due to the randomness and volatility of the output of wind power, it increased the demand and difficulty level of power auxiliary services. Therefore, facing with the rapid growth of the installed capacity of wind power, the traditional auxiliary services could not meet the demand of wind power grid-generation. In recent years, the grid-connected and integration issues of renewable energy generation, especially the wind power, has been becoming increasingly prominent in China, and loss of wind electricity in 2012 and 2013 reached up to 20.822 billion kWh and 16.233 billion kWh respectively. In order to solve the grid-connected and integration issues of wind power, the paper proposed that wind power provide the auxiliary services for electrical system.

In recent years, large numbers scholars have re-searched the wind power auxiliary services. Xuemin Feng (2009) and Meng Zhao (2012) mainly studied the feasibility of wind power frequency modulation and held that the wind turbines could participate in the system frequency modulation auxiliary services. Guangyu Zhao (2013) and Ning Chen (2011) researched the reactive power regulation of wind power and its strategy, and pointed out that wind power could provide additional reactive power support for power grid and maintain the voltage stability of regional power grid. Besides, Qinghai Sun (2012) and Ying Qiao (2013) studied the auto-matic voltage control of wind power. According the existed literature researches, the wind turbines can provide auxiliary services for power system. At present, although many scholars researched the evaluation of traditional auxiliary services [WANG Wei, 2010] [Zhou Xu, 2011] [Shaofeng Wei, 2004], there were few researchers to research the evaluation problems of wind power auxiliary services. Based on this, the paper would construct the evaluation index system and model of wind power auxiliary services, and study the evaluation problems of wind power auxiliary services. 


\section{THE EVALUATION INDEX SYSTEM OF AUXILIARY SERVICES OF WIND POWER}

\subsection{Market}

The objects and purposes of the comprehensive evaluation could directly determine the construction of index system and evaluation subsystem, and also effects on the selection of evaluation method, so it is necessary to definitude the evaluation objects and evaluation purposes firstly. Secondly, we need choose the method of building the evaluation index system, and then obtain the comprehensive evaluation index system. Based on the comprehensive benefit of wind power auxiliary services, the paper will evaluate the ancillary services of wind power from the four dimensions: namely the applicability, security, economic efficiency and Environment benefits. The comprehensive evaluation index system of wind power auxiliary services was composed of the four first class indicators and nineteen second class indicators (See Table 1).

Table1. The evaluation index system of auxiliary services of wind power

\begin{tabular}{|c|c|}
\hline First grade indexes & Secondary evaluation index \\
\hline \multirow{4}{*}{ Adaptability } & The total amount of wind energy resources $(y 1,1)$ \\
\hline & The proportion of wind power installed capacity (y1,2) \\
\hline & $\begin{array}{l}\text { The technological level of wind power auxiliary services } \\
(y 1,3)\end{array}$ \\
\hline & $\begin{array}{l}\text { The wind power installed capacity that can be used to provide } \\
\text { auxiliary services }(y 1,4)\end{array}$ \\
\hline \multirow{6}{*}{ Security } & Wind turbines response time $(y 2,1)$ \\
\hline & Frequency eligibility rate (y2,2) \\
\hline & Voltage qualified rate (y2,3) \\
\hline & Power cut time $(\mathrm{y} 2,4)$ \\
\hline & Valley-to-peak (y2,5) \\
\hline & The equivalent forced outage rate of wind turbines $(y 2,6)$ \\
\hline \multirow{5}{*}{ Economic efficiency } & The equivalent available factor of wind turbines $(\mathrm{y} 3,1)$ \\
\hline & Thermal power unit longevity variation $(y 3,2)$ \\
\hline & The auxiliary service cost of wind power $(y 3,3)$ \\
\hline & Carbon emission reduction benefits $(\mathrm{y} 3,4)$ \\
\hline & The on-grid electricity quantity of wind power $(y 3,5)$ \\
\hline \multirow{4}{*}{ Environmental benefits } & The energy conservation (y4,1) \\
\hline & Nox emissions reduction $(\mathrm{y} 4,2)$ \\
\hline & Sulfur dioxide emissions reduction (y4,3) \\
\hline & carbon dioxide emissions reduction $(\mathrm{y} 4,4)$ \\
\hline
\end{tabular}

(1) Applicability

Adaptability is the ability that wind power copes with the requirements of power auxiliary service. The paper chose the four indexes, namely the total amount of wind energy resources, the proportion of wind power installed capacity, the technological level of wind power auxiliary services and the wind power installed capacity that can be used to provide auxiliary services, to evaluate the applicability of wind power auxiliary services. The applicability can be used to evaluate whether the wind power auxiliary services compatibles with the development of wind power industry or not, based on the rapid growth of wind power installed capacity and the status quo of power auxiliary services. 


\section{(2) Security}

The security mainly refers the security and stable operation of grid system, and reflects the effects of wind power auxiliary services on the power grid safe operation. The paper selected the six indexes to evaluate the security of wind power auxiliary services, including the wind turbines response time, frequency eligibility rate, voltage qualified rate, annual power cut time, the valley-topeak of electrical load and the equivalent forced outage rate of wind turbines.

(3) Economic efficiency

The Economic efficiency is defined as: the wind power auxiliary services create economic efficiency for the power system. The economic effectiveness is one of the main contents to evaluate the feasibility of wind power auxiliary services. Based on the influence of wind power auxiliary services on the power system and environment, the paper chose the five indexes to evaluate the economic effectiveness of wind power auxiliary services, including the equivalent available factor of wind turbines, the longevity variation of thermal power units, the auxil-iary services cost of wind power, the carbon emissions reduction benefits and the on-grid electricity quantity of wind power.

(4) Environmental benefits

The environmental benefits reflect the influence of wind power auxiliary services on the environment. As the environment pollution was becoming increasingly serious and the energy conservation and emissions reduction policies were implemented, the assessment of environment benefits plays an increasingly important role in the comprehensive evaluation of wind power auxiliary services. The paper selected the four indicators of energy conservation, Nox emissions reduction, Sulfur dioxide emissions reduction, and carbon dioxide emissions reduction to evaluate the environmental benefits of wind power auxiliary services.

\section{COMPREHENSIVE EVALUATION THEORY AND METHOD}

\subsection{Structural equation model}

The paper used the SEM to build the comprehensive evaluation model of wind power auxiliary services, in order to promote the research and development of intermittent energy auxiliary services. As important statistical method and research method in contemporary social science fields, the SEM blended the statistical techniques of traditional multivariate statistical analysis, namely "Factor analysis" and "linear model regression analysis", and solved the problems that lots of traditional statistical methods cannot solve. Besides, the SEM defined the relationship among the dominant variables, potential variables and errors, and we can obtain the direct effect, indirect effect and general effect of independent variables on the dependent variable in the SEM. Based on the general idea of SEM and the characteristics of auxiliary service, the comprehensive evaluation of wind power auxiliary services were divided into three steps: Firstly, according to the theory and research results, put forward the theoretical model and construct the SEM. Secondly, test the rationality of theoretical assumption of the comprehensive evaluation system from a data perspective. Finally, modify the original model on basis of the inspection results, in order to improve the goodness of fit between evaluation model and data, and then use the final model to evaluate the auxiliary service ability of wind power. The paper mainly researched the first step, namely the construction of the theoretical model and SEM of wind power auxiliary services evaluation.

In view of the related evaluation researches of auxiliary services, the paper held that the auxiliary services ability of wind power was mainly influenced by the adaptability, security, economic efficiency and environmental benefits. Therefore, the paper constructed a second order factor model (See Fig. 1). Thereinto, the second order factor was the ability of wind power auxiliary services, and the first order factors were made up of the adaptability, security, economy efficiency and environment benefits. 


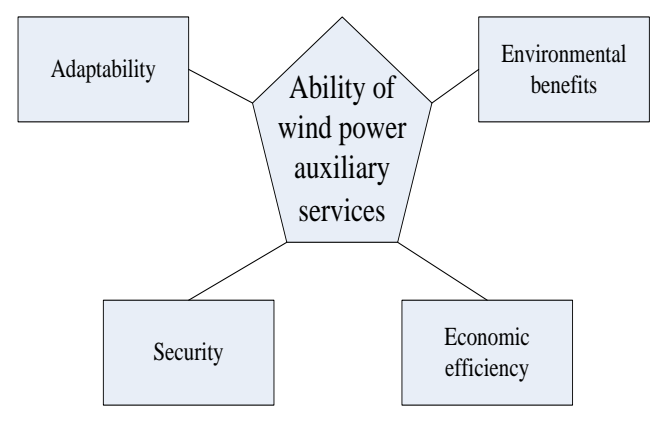

Figure 1. The comprehensive evaluation theoretical model of wind power auxiliary services.

\subsection{The construction and identification of the SEM}

Based on the theoretical model and evaluation index system of wind power auxiliary services, the paper constructed the SEM of wind power auxiliary services (See Fig. 2). The SEM of wind power auxiliary services evaluation was a second-order confirmatory factor model and decided by the following two equations [Hau K T, 2004]:

$$
\begin{gathered}
\mathrm{y}=\Lambda_{y} \eta+\varepsilon \\
\eta=\Gamma \xi+\varsigma
\end{gathered}
$$

Thereinto, the ability of wind power auxiliary services was exogenous latent variables $(\xi)$, the adaptability, security, economy efficiency and environment benefits were endogenous latent variables $\left({ }^{\eta}\right)$, and the 19 secondary evaluation indexes were observational variables (Xi,j). $\varepsilon_{\text {was }}$ the measuring residual error that the observational variables cannot be entirely interpreted by latent variables, and $\zeta$ was the estimation error what the endogenous latent variables weren't entirely interpreted. $\quad \Lambda_{y}$ was the regression matrix that the observational variables were interpreted by latent variables, namely the load factor from $\eta_{\text {to }} y$. $\Gamma$ was the regression matrix that the endogenous latent variables were interpreted by exogenous latent variables, that is the regression matrix from $\eta_{\text {to }} \xi$.

The SEM identification is related to whether the parameters of the model can be identified or not. The parameter identification can be divided into recognizable and unrecognizable, and the former includes just identification and excessiveness identification. When an unknown parameter can be expressed by the representative function of the one or more elements of observation variables' variance covariance matrix, the parameter is identified. The former is just identification, and the latter is excessiveness identification. If the all parameters of model are just identified, then it is just identified model. If the model includes the excessive identification of parameters, then it is excessive recognition model. Besides, if the model includes unidentifiable parameters, then it is unidentifiable model. The model identification is connected with construction of the model instead of samples; both small degree of freedom and the interaction between variables can lead to the model unrecognizable [Fangming Huang, 2005].

The SEM can provide a clear logical relation for the further researching on the evaluation of wind power auxiliary services, and the analysis flow of the SME was shown in the Fig.3 [Jianning $\mathrm{Li}, 2004]$. Firstly, the researchers can design the questionnaire for the evaluation of wind power auxiliary services, and then collect the evaluation data by distributing and recycling the questionnaire of wind power auxiliary services evaluation. Secondly, the investigators can use the LISREL8.80 software to verify, discern and correct the SEM of wind power auxiliary services evaluation by the fitting analysis of data, and then obtain the comprehensive evaluation model of wind power auxiliary services. Finally, the researchers can use the comprehensive evaluation model to evaluate the wind power auxiliary services after collecting the practical operation data of wind power auxiliary services. 


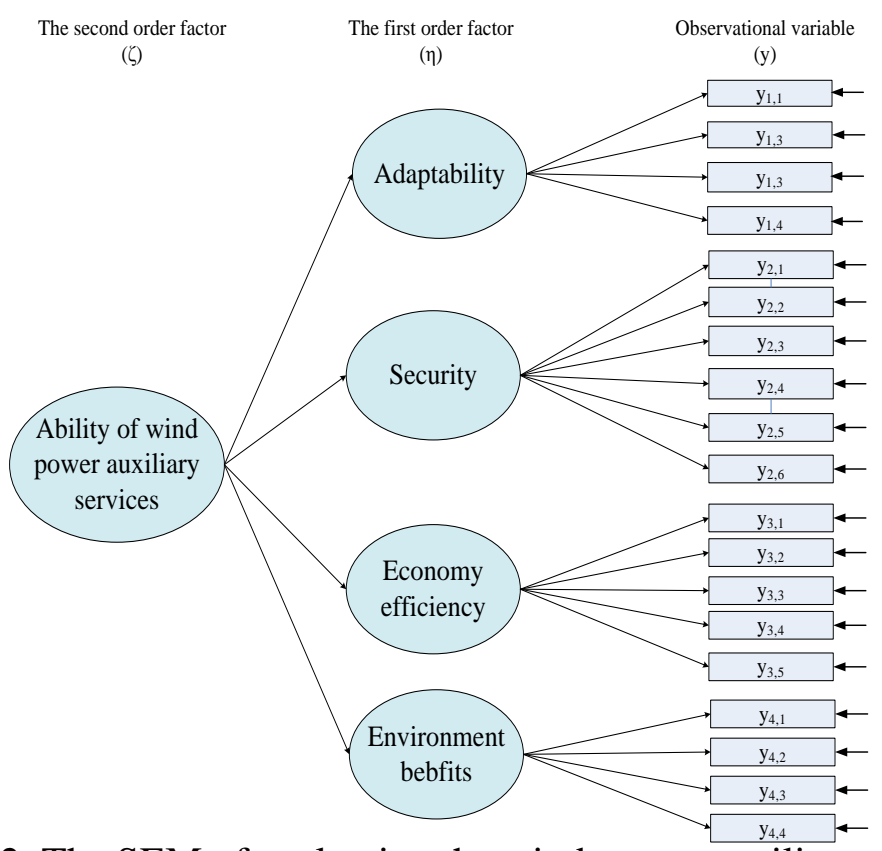

Figure 2. The SEM of evaluating the wind power auxiliary services.

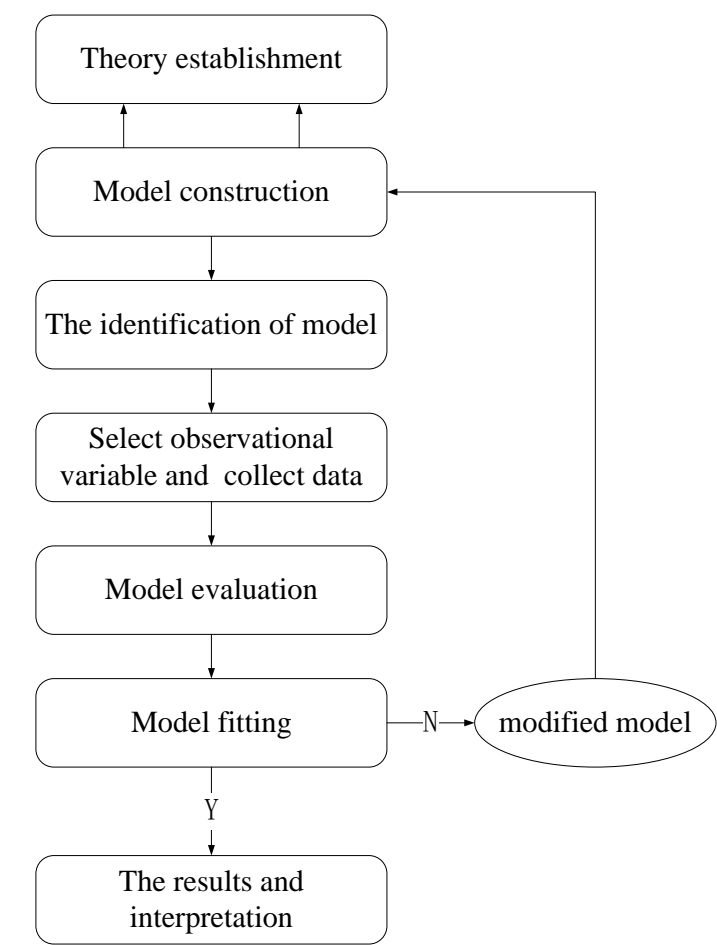

Figure 3. SEM analysis flow of wind power auxiliary services.

\section{CONCLUSION}

The rapid development of wind power increased the difficulty of the traditional auxiliary services, and leaded to serious wind curtailment phenomenon. In order to improve wind power integration, the paper held that wind turbines take part in the auxiliary services of power system. As for the evaluation problem of wind power auxiliary services, the paper constructed the evaluation index system and SEM. Besides, the paper studied the identification of the evaluation model. According to the analysis, the SEM can be applied to the evaluation of wind power auxiliary services. The research on the evaluation of wind power auxiliary services was a basic research and innovative attempt, and provided a scientific evaluation model for the development of wind power auxiliary services. 


\section{ACKNOWLEDGMENT}

This article is supported by "Science and technology project funding by State Grid Liaoning electric power co., LTD. Benxi Power Supply Company” (Grant No. FZJS1400820 and FZJS1400829).

\section{REFERENCES}

[1] Xuemin Feng et al. 2009. Simulation of Double-Fed Wind Generator Participating in Auxiliary Frequency Control. Electric Power and Electrical Engineering 3(29): 9-12.

[2] Meng Zhao. 2012. New Control Strategy of Variable-speed Constant-frequency DFIG Wind Turbines' Participation in System Frequency Regulation. North China Electric Power University.

[3] Guangyu Zhao et al. 2013. Reactive Power Regulation Performance of Double-fed Wind Turbine. Wind Energy 2:84-87.

[4] Ning Chen et al. 2011. Design and Application of Reactive Power Control System for Wind Farm. Automation of Electric Power System 23(35): 32-36.

[5] Qinghai Sun et al. 2012. The application of automatic voltage control device in wind farms. Inner Mongolia Petrochemical Industry 3:31-32.

[6] Ying Qiao Lu et al. 2013. Performance Evaluation Method of Wind-coal Coordinating Operation. Automation of Electric Power System 17(37): 1-8.

[7] WANG Wei et al. 2010. Evaluation Index System and Method of Pumped-Storage Power. Power System and Clean Energy 8(26): 88-92.

[8] Zhou Xu et al. 2011. Evaluation system for regional ancillary services of power market. Journal of Electric Power Science and Technology 1(26): 86-91.

[9] Shaofeng Wei. 2004. Economical appraisal and industrial policy analysis for Pumped storage station (PSS). North China Electric Power University.

[10] Hau K T et al. 2004. Structural Equation Model and Its Applications. Beijing: Educational Science Press.

[11] Fangming Huang. 2005. Structural equation model theory and application. Beijing: China Taxation Publishing House.

[12] Jianning Li. 2004. Introduction to structural equation model. Hefei: Anhui university press. 